\title{
Supplying Basic Education and Learning to Sub-Saharan Africa in the Twenty-First Century
}

\author{
Idowu Biao, ${ }^{1, *}$ \\ ${ }^{1}$ Department of Adult Education, University of Botswana, Botswana \\ *Correspondence: Department of Adult Education, University of Botswana, Botswana. Tel: 267-7435-9491. E-mail: \\ idowubiao2014@gmail.com
}

Received: March 26, 2018

Accepted: April 9, $2018 \quad$ Online Published: April 25, 2018

doi:10.5430/wje.v8n2p181

URL: https://doi.org/10.5430/wje.v8n2p181

\begin{abstract}
This article posits that schooling in Sub-Saharan Africa has so far failed to yield the results expected of it on two grounds. First, the population of persons accessing both basic education and other levels of education is negligible in comparison with those who ought to access them (1 out of every 4 primary school age children; less than half of the qualified secondary school students; about $7 \%$ gross enrolment within higher education). Second, schooling has failed to deliver the kind of socio-economic development expected in the case of Sub-Saharan Africa as a high prevalence of poverty still exists and incongruity continues to exist between the education provided and the livelihoods of Sub-Saharan Africans. Using this poor educational and development performance as justification, a more utilitarian, relevant and sustainable approach to basic education and learning is recommended for Africa going forward. This recommended approach combines both the current school system with a special non-formal education system for the purpose of delivering basic education and learning in Sub-Saharan Africa in the twenty-first century.
\end{abstract}

Keywords: basic education and learning in Africa, schooling and socio-economic development in Africa, Sub-Saharan Africa, learning and livelihoods, twenty-first century

\section{Introduction}

Even the first human being learnt. This submission underlies the primordial importance of learning or education not only for human survival but for the purpose of facilitating and sustaining continual physical, social, cultural, psychological and economic development. Although the first human being had no other human being to learn from or to learn with, he necessarily found it indispensable to learn techniques and strategies for coping with the challenges offered by the earth, his new habitat (Biao, 2013a pp.16-70). These challenges included the need to protect himself against wild animals and hostile environmental conditions. They also included the need to eat safely and the need to provide for his continual survival within a new living environment. Thus, from time immemorial, learning has been found to be indispensable for human survival and development efforts.

Consequently, all human societies everywhere were founded upon some system of education and learning which perpetually got challenged not only by continually developing natural circumstances but also by conquests, wars and other sociological factors. Sub-Saharan Africa possesses an original system of education that has been variously referred to as traditional African education, indigenous education and pre-historic form of education (Gordon, 2011; Keita, 2011; Ki-Zerbo, 1991). However, as it was to be expected, this system has been challenged and influenced by countless circumstances and other systems of education. One system of education that has had a profound impact on the African system of education is the Western type of education that is also known as the school system of education or simply, 'education'. Sub-Saharan Africa effectively began supplying the Western education type to its citizenry in a massive manner, around the nineteenth century during the colonization years. Consequently, the promotion of both basic education and other levels of education in Africa was carried out through the school system from inception through the independence years. However, beginning from the last two decades of the twentieth century, studies revealed that, as a result of a combination of factors (economic recessions, poor governance, etc.), only one quarter of school age children find placement into primary/basic education schools (Torres 2003; Biao, 2013b, 1991). About a similar low rate of clients get placement into secondary (UNICEF, 2016) and tertiary institutions (Teferra, 2015; Tilak, 2009). 
Having realised that the period lying beyond the twentieth century would demand that a critical population size be educated if social and economic development is to be guaranteed, Sub-Saharan Africa, assisted by development partners, began to explore additional education avenues mainly within the non-formal educational environment (Fiske, 2000; UNESCO, 1990). The 2015-30 United Nations Sustainable Development Goals project has come to add impetus to this search for development-promoting education when it promulgated its 17 -goal agenda shortly before the expiration of the 2000-15 Millennium Development Goals project. While the call for massive access and participation in education is a laudable one, the insistence on supplying most of the education needed by Africa through the school is here judged as a faulty approach to linking education to development within the Sub-Saharan African context.

This article discusses the peculiar social, educational and economic circumstances of Sub-Saharan Africa with a view to suggesting the most cost-effective approaches to basic education supply that holds the potential not only for a short term developmental gain but for a long and sustainable linkage between educational practice and socio-economic development.

\section{Theoretical Framework}

Economists imposed their own concept of development to the world for more than two centuries. From the time of classical economists to the period of neo-liberalists transiting through neo-classical economists and human development index economists, the world learnt that development implies the amassing of monetary and material capital in varying degrees. According to classical economists, any society that can interactively utilise the assets possessed by monetary capitalists (capital owners), material capitalists (land owners) and workforce (labour owners) would have set into motion, a process of development (Malthus and Ricardo, 1817). Neo-classical economists replaced classical economists' land ownership with resources (technological equipment and knowledge) to enunciate their own capital-technology-labour theory of socio-economic development (Blaug, 1978). Liberal economists suggest that society would develop faster and more stoutly when it is completely open to competition and private enterprise with boundless initiatives expected to be emitted by individuals or/and groups of individuals (Balaam and Dillman, 2015). However, while acknowledging the benefits of liberal economics, neo-liberal economists warn that unchecked liberalism can hurt weak individuals or groups of individuals in society. They therefore advocate for some measures of official interventions aimed at protecting weak individuals or institutions within society against the excesses of cut-throat competition (Turner, 2008).

Additionally, all that is ultimately appreciated and accepted as socio-economic development is in reality a product of a deliberately designed and promoted educational plan and system. Thus, classical economic, neo-classical economic, liberal economic and neo-liberal economic models of socio-economic development would naturally materialise in an environment in which majority of society members have had the opportunity to be schooled in the theories and practices of these models of development.

Although the afore discussed theories of development emphasise monetary capital as means to development, socio-economic development is not all about monetary wealth and material accumulation. It is equally about cultural capital and a world view of a people. Consequently, both in the Global North and the Global South, a cultural capital underpins all socio-economic development. This cultural capital according to Blunden (2012), Nsamenang (2006) and Berger and Luckmann, (1991) is propagated through education and learning and it defines the totality of the individual including his organic inheritances (hereditary traits) and mode of socialisation.

\section{Statement of the Problem}

The expectation of both Sub-Saharan African governments and the international community is that African economy should be wholly integrated into the world economy. Many decades have been spent in setting up educational, economic and social structures whose aim is to achieve this objective. In the main, the educational structure relied upon for this purpose is the school system. The economic structures deployed are those who are hooked on to the global political economies proposed by the classical, neo-classical, liberal and neoliberal economists. The social structures invented to achieve the integration of African economy into the global economy include international non-governmental organisations such as United Nations bodies (UNESCO, UNICEF, UNFAO, etc.) and other specific nations based international organisations such as USAID, DFID, DVV/IZZ and such others.

If the assumption remains that cultural capital (organic inheritances and modes of socialisation) and education (schooling and learning outside of the school) underpin all socio-economic development, it is logical to assume that the expectation of both African governments and the international community is based on the assumption that one 
same modus operandi and performance of cultural capital and education is obtainable in both the Global North and Global South. Unfortunately, no data support the assumption that one same modus operandi and performance of cultural capital and education exists in both the Global North and Global South. On the one hand, extreme individualism is a hallmark of the mode of socialisation within the Global North whereas community living and African humanism are guideposts for socialisation in Africa. On the other hand, contrary to the countries of the North where $96 \%, 85 \%$ and about $40 \%$ enrolment and retention are achieved at the primary, secondary and tertiary education levels (OECD 2015), after about one and a half centuries of modern education in Africa, only one out of every 4 school age children is in the primary school. Between 2000 and 2015, about $90 \%$ primary school enrolment was achieved in many African countries (following the support received through the 2000-15 MDGs), however half of the enrolled learners dropped out before completion (United Nations, 2015). As though the low primary school performance was not bad enough, less than half of secondary school age learners are in school in Sub-Saharan Africa (UNICEF, 2016) while only about $7 \%$ of qualified tertiary education learners find a place within the tertiary education sector on the continent (Teferra, 2015 \& Tilak 2009). Yet, only a higher percentage of tertiary education graduates possess the skills and ability to drive socio-economic development in the twenty first century. Only a critical size (30-40\%) of graduates could have reached a high enough level of mental processing capacity with which to create knowledge and apply information with a view to effecting positive change within society.

...the diverse and growing set of public and private tertiary institutions in every country......forms a network of institutions that support the production of the higher-order capacity necessary for development (World Bank, 2015 para 3).

A number of factors including availability of only low financial resources (Tilak, 2009) incongruity between the philosophies promoted by African higher education sector and African living realities (Biao, 2013b), low critical thinking ability among tertiary education learners (Akinyemi, Ofem \& Ikuenomore, 2012), lack of accurate market information (Bassey \& Atan, 2012; Babalola, 2007) and mismatch between tertiary education and labour types required by the market have been identified as contributing to the stunted growth and/or inability of the African higher education to impact positively African social and economic environment.

\section{Analysis of the Sub-Saharan African situation}

This catalogue of cultural and educational differences between the Global North and the Global South constitute enough basis for faulting African governments' expectation and for calling for a rethink of the African development strategy. Culture and education being central to development, these two concepts need to be reviewed within the context of Sub-Saharan Africa.

There exist numerous definitions and even concepts of culture. Yet, all of these definitions and concepts tend to suggest that culture, apart from expressing itself in a tangible behavioural pattern, is equally a process of education and learning. This idea is reflected by (sagepub, 2017) when it submits that culture is:

...transmitted and created content and patterns of values, ideas, and other symbolic-meaningful systems as factors in the shaping of human behaviour (Kroeber and Parsons 1958 as cited in sagepub, 2017 p.10].

In other words, culture is education but one which seeks to inculcate values and symbolic systems that ultimately crystalise into specific world views. Schooling is another form of education. But one form of education which is a significant symbolic system derived from Western (Global North) culture and whose functional utility is the continuous re-transmission of Western culture. Under a condition, such as this, the supply of basic education as it is currently conceived and carried out is nothing but the transmission of Western culture to a group of non-Westerners (Sub-Saharan Africans). There is absolutely nothing wrong in one people passing on its knowledge, know-how and even attitude to another people. The nonstrategic and uncritical fashion through which this transmission is carried out is the issue.

When an African child is taken through modern basic education within a school system as would a European child, there is something uncritical and nonstrategic about this approach to the supply of education to Africa in the twenty-first century. This approach to education denies the existence of human ontogenesis (innate and social factors impacting learning) discussed by Nsamenang, (2006). One is not minimising the modest achievements so far realised in the fields of the use of mother tongue (or language of immediate environment) in education (Kioko, 2015 Kayaoglu, 2012). Neither is one unmindful of the efforts in establishing child friendly primary and basic education schools all over Africa (UNICEF, 2008). One is also not ignoring the positive initiative that is providing at least one meal to many primary school children in Africa (Lawrence-Brown, 2017). 
Yet, in spite of all these and other efforts that aim to improve the supply of basic education, many gaps remain to be filled before modern basic education can become a success story in Sub-Saharan Africa.

\section{Quo Va dis?}

To begin to seek solutions to the intractable cycle of basic educational failure in Africa, the meaning and purpose of basic education must be brought into sharp focus. As the name implies, basic education is that type of education provided with a view to enabling individuals and societies begin to obtain an initial understanding of the world they live in and the basic components making up their world environment. Consequently, basic education ought to supply individuals with traditional literacy skills (skills for reading, writing and numeracy), the understanding of their social milieu (story of the social fabrics and landmark events accounting for the existence of their society), basic scientific understanding of how the world around them functions and livelihood opportunities existing within their milieu.

However, in truth and in practical terms, international definition and provision of basic education does not include the livelihood component mentioned above. For example, the thematic framework that led to the adoption of the international operational definition of basic education discussed the following:

i. $\quad$ The place of elementary education and fundamental education in basic education.

ii. The levels of education (early childhood care and development, primary, junior secondary education) covered by basic education.

iii. The possibilities of making basic education free and compulsory in all UN member states.

iv. The formal and non-formal natures of basic education.

v. Contents and objectives (basic learning skills and needs, interface with basic technical and vocational education and training) of basic education (UNESCO, 2007 p.1-2).

As can be noticed, no element of the framework addressed the issue of livelihood. Item ' $\mathrm{v}$ ' that discussed interface with basic technical and vocational education and training did so within the context of youth education wherein any basic vocational education and training offered during the course of basic education may constitute only a foundational step towards a future substantial vocational and professional training. This distancing of basic education from livelihood issues existed within the original effort at endowing the world with an international concept of basic education. After the 1990 World Declaration on Education For All (EFA), the international community decided to set a basic threshold for education worldwide. Consequently,

In its Report presented to UNESCO "Learning: The Treasure Within" (1996), the International Commission on Education for the Twenty-first century, stated that "Basic education is the first step in attempting to attenuate the enormous disparities affecting many groups - women, rural populations, the urban poor, marginalized ethnic minorities and the millions of children not attending school and working” (UNESCO, 2007 p.3).

Yet basic education needs neither be wholly school based nor be divorced from livelihood provision. This is because on the one hand, majority of persons needing basic education in Sub-Saharan Africa ( $4 / 5$ of school going age children, adult illiterates and semi-literates) are either not in school or are too old to be in school. On the other hand, as a result of a high prevalence of poverty (50\%), livelihood issue is central to life and living in Sub-Saharan Africa. Which objectives should basic education seek to achieve in Africa then and who should its target audience be?

\section{Objective of Basic Education}

It is neither logical nor rational to expect poor and hungry people to be motivated to learn pieces of knowledge that hardly address their survival concerns. The laudable initiatives of education through mother tongues, operationalization of friendly schools environment and 'one meal a day' at school are nothing but token initiatives compared to the vast majority of potential basic education beneficiaries that are not served by these initiatives.

Consequently, the basic education appropriate to the context of Sub-Saharan Africa is one that should possess two characteristics. First, it should be one that can impact majority of Sub-Saharan Africans (children, youths and adults). Second, it should be one which, in addition to the basic skills of reading, writing, numeracy and life skills, prioritises region and community based livelihood needs and practices. Implied in the nature of this kind of objective is the fact that the clientele and livelihood needs and practices of potential basic education beneficiaries will be highly varied. 


\section{Clientele of Basic Education in Sub-Saharan Africa}

The varied and multi-group clientele to basic education on the continent is spread all over large geo-political and cultural entities. Depending on whether they are found in the vicinity of nations' Capital Cities, and whether they are located in the southern, northern, western or eastern parts of their countries, their experiences and learning needs may differ. For example, within the most populated country of Sub-Saharan Africa (Nigeria), it has been found that a significantly large population residing in the northern end, is either averse or indifferent to modern education as it now offers itself. In the east, after an initial post-independence interest in modern education, education is currently used as secondary and an appendage to other livelihood practices (e.g. trading in goods of first necessity and street trading). In the west where school achievement remains a symbol of medium or high social status, some amount of school learning for the sake of learning remains tolerated. Additionally, depending on whether an individual lives in the rural or urban area in Nigeria or other countries of Africa, his attitude would not be the same towards schooling or modern education in general. Each of these differences that impact attitude towards schooling or modern education in these countries of Africa are the results of lingering intimate social, political, religious and ecological experiences had by the varied inhabitants of this continent. These experiences are so strong and so intimate that one hundred and a half years of the promotion of modern schooling have not been able to alter them significantly.

For example, the northern part of Nigeria came into contact with Islamic religion about one thousand years ago ( $11^{\text {th }}$ c.AD) (African Studies Centres, 2016). This Islamic link got renewed a number of times through numerous Jihads (Holy Wars), the most recent, memorable and successful Jihad being that of Uthman Dan Fodio during the $19^{\text {th }} \mathrm{c}$.AD (African Studies Centres, 2016; Callaway \& Creevey, 1994; \& Umejesi, 1992). On-going Boko Haram skirmishes in that part of the country cannot be said to be a successful Jihad. Europe began to impact the socio-political landscape of Africa and Nigeria about the $19^{\text {th }} \mathrm{c}$. and Lord Frederick Lugard (The most influential British Governor of pre-independence Nigeria) skilfully used the influence of Islam in northern Nigeria (through Indirect Rule) to keep the restive pro-independence southern Nigeria in check and to keep Nigeria governable longer than it would have otherwise been possible (Crowder, 1980). Unfortunately this same factor that Lugard used to advantage within the realm of politics came to constitute itself into a clog in the wheel of modern education emancipation in the north for a long time. This situation is logically bound to continue unless future educational approaches and planning harness the dynamics existing among religion, politics and society. Which of these three phenomena exerts the most influence on national or regional education systems? Judging from current situations in northern Nigeria and Senegal, two West African societies in which Islamic religion is predominant, it does appear politics has the capacity to harden or soften religion against modern education. In Senegal where the French implemented a colonization philosophy of 'assimilation' (All living within the colonized territories are presumed to be French before being Africans or citizens of their respective nations), there is a greater sympathy and tolerance towards modern education than there is in northern Nigeria where the British implemented a colonization philosophy of 'indirect rule'.

Does religion shape society less or more than society shapes it? Less, according to this solidly researched study of the comparative status of Muslim women in northern Nigeria and Senegal. Historically and geographically less exposed to Western influences than Senegal, northern Nigeria today secludes women and bars them from public life, whereas Senegalese social and religious norms are less discriminatory. In Senegal, Muslim women have achieved at least a toehold in the modern sector, and a feminist agenda is supported by a nascent women's movement. By contrast, in northern Nigeria (where women were denied the vote until 1976 and today less than one percent attend universities today), patriarchy and social conservatism are so pervasive that women's only hope of advancement, the authors argue, lies in promoting gender equality as a matter of reform within Islamic law, or sharia. Muslim fundamentalists, who use different interpretations of sharia to justify their opposition to equality, are striving in both countries to roll back even the minor gains of Muslim women; But here again, the authors predict, the greater openness of Senegal to modern economic and social influences (as well as the buffer against fundamentalism provided by Muslim brotherhoods) make Senegal less likely than northern Nigeria to be swept by fundamentalist reaction. - Gerhart, 1995 para.1).

The Nigerian civil war (1967-70) did impact attitude towards modern education in a peculiar way in the eastern part of Nigeria. Whereas the social worth and both extrinsic and intrinsic values of education remained appreciated after the civil war, it was the issue of livelihoods and regional reconstruction that predominated and gained the most attention. As such, the acquisition of modern education was relegated to second rank for a few years after the war and when educational checks were run later, it was found that more girls than boys were in schools in eastern Nigeria (UNICEF, 2008), boys and men being busy trading with a view to providing livelihood for the family. The western section of Nigeria was not quite impacted by the civil war so, modern education continued its upward trend, limited only by low financial allocation and underdeveloped infrastructures. 
In most countries of Sub-Saharan Africa, the supply of basic education is impacted by one form of social, cultural and ecological issue similar to the situation in Nigeria. Together, these issues define the specific basic skills and livelihood practices existing within Sub-Saharan Africa. Importantly, these issues equally define the specific groups of potential learners that can benefit from a basic education curriculum built around basic skills and livelihood practices relevant to sections of Sub-Saharan Africa. The conclusion here therefore is that there may not be a single and uniform basic education curriculum for the whole of Sub-Saharan continent.

\section{Identifying Target Learner Groups}

Studies conducted in Nigeria, Mali and Benin have revealed that, as a result of geographical, cultural, vocational, psychological and educational reasons, there exist a large number of special groups needing basic learning in Africa (Hagnonnou, 2005; Biao, 2015). These special groups include the Girl-Child, the out-of-school boy, the Quranic school child and the Pudah woman. Other groups include the nomad and the bushman.

The Girl-Child is a female child usually between the ages of 6-12years who instead of being at school is in the streets hawking fruits, nuts or wares. She is economically important to the family because on the one hand, her hawking activities do supplement family income; on the other hand, the fact of her being a girl that would soon grow into a marriageable adolescent or adult (whichever is the community practice) constitutes the second potential source of income. The out-of-school boy is usually a school age male child who, instead of being in school, is learning a trade either within the area of modern and luxury goods trading or in some vocational apprenticeship. In each of the two cases, the calculated returns on investment as they are perceived by his parents and family members are cost-effective as the training period would usually be shorter than that offered by the school and post-training employment and/or self-employment opportunities are about $95 \%$ more assured than in the case of schooling. The Quranic school child is either a girl or boy who is registered quite early in life into Quranic schools with a view to having him graduate into a preacher or some sort of Islamic religious leader and her, into a virtuous marriageable young girl. The Pudah woman is usually a married woman who remains behind the closed doors of her matrimonial home most of the days, weeks, months and years of her life. If she must leave her home (she has no reason to, as the husband is on hand to run all her errands and provide all her needs), she could leave under the cover of the night or during the day covered from head to toe. The nomad is usually a herdsman, fisherman or a farmer who moves from place to place in search of grazing patches for his cattle, bodies of water for the purpose of fishing or for seasonal land tilling contracts. The nomad lives by this and he pays his taxes and all other incidental expenses from his activities. The 'bushman' refers to a whole community of persons who live in the woods or bush and who primarily are hunters.

These are splinter groups indeed. However, as numerous as they may be and as strong as the temptation may be to merge these groups into a single large whole for basic educational purposes, these groups remain socially meaningful, culturally relevant, economically viable and educationally teachable only as they stand at present. Unless there exists in some mind the notion that education can be forced down the throat of a people, a more logical thinking would be that no education may be divorced from the social realities of the society within which resides its recipients (Berger and Luckmann, 1991). Therefore, each of the special groups afore mentioned, living within specific social realities, would tend to identify with and continuously contribute to the sustenance and perpetuation of these realities until such a time it is logically and humanly demonstrated to them why they need to shift in their stand. This potential shift in stand is better brought about through the promotion of a humanistic approach to education and learning. This humanistic approach is one that should take into consideration the current contributions of the potential learner to his/her society, the current responsibilities that the potential learner bears towards his/her own sustenance and wellbeing and those of other persons that depend on him/her and the world view of the future learner. The inability to take into consideration the afore mentioned factors in the process of the supply of basic education in Africa, contributed and continues to contribute to the massive failure so far registered. This is not the first time that attention is drawn to these facts. A number of critical thinkers including Krätli, (2001) had made this appeal in the past.

Educationally, pastoralists appear to be a paradox. From the point of view of official education they are a complete failure: in terms of enrolment, attendance, classroom performance, achievement, continuity to higher education and gender balance they regularly score at the bottom of the ladder. However, pastoralists although poor (some of them) are far from being a mass of drifting unskilled under-class..... On the contrary, as a necessary requirement for their livelihood in the drylands, pastoralists perform every day high levels of individual and social specialisation. They can be very confident, articulate and entrepreneurial, have good negotiating and management skills, and show a strong sense of dignity and self-respect (Krätli, 2001 p.1).

Without claiming that the aforementioned characteristics of the pastoralist's education is in itself self-sufficing in the 
$21^{\text {st }}$ century, Krätli (2001) suggested that such issues as social and economic marginalisation, lack of political representation or challenges raised by globalization can be included in the curriculum of the education for the pastoralists.

Therefore, for all intent and purposes, there exist different groups of learners whose learning needs are by necessity divergent within the context of developing societies, including Sub-Saharan Africa. Consequently, the learning contents (curriculum/programme contents) need to reflect this necessary and obvious divergence.

\section{Determining Appropriate Curriculum Content}

One of the first effective principles of teaching that the student-teacher (facilitator) learns is that learners learn better when they are taught from the 'known' to the 'unknown'. In other words, the motivation to learn is highest when the learner is led from that which $\mathrm{s} / \mathrm{he}$ already knows something about to the subject $\mathrm{s} / \mathrm{he}$ knows little or nothing of. Within the current context, the 'known' will be that phenomenon that guarantees the potential learner's sustainability and wellbeing (his/her livelihood) while the 'unknown' will be the type of education that the state/government wishes to equip him/her with (basic education as it is currently dispensed).

Where the curriculum content of basic education could be built around the pre-basic education life style of the individual (those factors upon which his/her pre-basic education wellbeing relies), education has a chance to succeed. This proposition is not in itself a new one. A number of similar initiatives have been promoted in the past (Ojokheta, 2007, Diop et.al, 2004 \& Gomez, 1971). A number of these initiatives did succeed in yielding positive results. However, they could not go on over a long time as a result of lack of required support by authorities in various states of the continent. Yet, this is an approach to basic education that links well livelihood practices to learning and one which is more appropriate to the circumstances of Sub-Saharan Africa.

\section{Identifying Appropriate Learning Methods}

By learning method, it is meant the manner in which learners could be organized or arranged for the purpose of partaking in learning activities. Should learners be organized in a traditional class sitting formation or in very small groups (tutorials of 2 or 3 learners), in small groups (12-15 learners) or medium groups (16-50 learners) or large groups (50-above). Identifying appropriate methods equally implies the selection of venues within which learning may take place without offending the cultural and religious sensibilities and social statuses of learners. Should these venues include formal school environments, religious venues, community centres or other public places? Should these learning sessions hold during the day or night? Should children, youths and the elderly be attended to, using the same venue and period? These are a few of the many questions that the developers of the recommended approach to learning are called upon to answer before rolling out the initiative. Suffice it to say that the nature and composition of each target group of learners would be of assistance in arriving at accurate answers to these questions. For example, whereas it may be culturally and vocationally acceptable to discuss milk processing or animal husbandry with children, youths and the elderly in attendance, it may not be wise to lump all these same groups together when facilitating the learning of English language or the language of the immediate environment or many of the aspects of modern basic education curriculum. The justification for this distinction is to be sought within the philosophy of African lifelong learning. The learning of house chores or errand running (through practice or imitation) even at a tender age is a process of equipping the young with both a notion of social responsibility and a sense of dignity of labour. This is one reason why the recommended approach to future learning programs in Africa needs to reconcile understandings of a number of educational concepts (Early Child Education and Development [ECED], Adult Learning, etc.) within both the frames of African lifelong learning and modern school education on the outset.

\section{Identifying Appropriate Learning Techniques}

A learning technique within the context of the present discussion means a style of communication chosen by a learning facilitator on the basis of its ability to most effectively promote communication and learning. These techniques may include the lecture, flexible lecture, demonstration, discussion and /or dialogue techniques of facilitating learning. They may also include other community learning techniques such as project based learning and community language learning techniques.

The appropriateness of a learning technique would depend on the type of subject or theme that is selected for discussion. For example there are themes that are amenable to the employment of the demonstration technique (practical work, mechanical tasks, etc.) while the understanding of others are better facilitated by the lecture 
technique (explanation of words and concepts). Yet, the understanding of other tasks (conflict resolution, problem solving) is better facilitated by either the dialogue and/or the discussion techniques.

\section{Budgeting}

One advantage that this recommended approach to learning holds is that the cost of basic education can now be shared between beneficiaries and African states. One reason usually advanced on the continent for the inability of government to sponsor basic education nation-wide is unavailability of funds. However, when as recommended, basic education includes aspects of the livelihood and/or life passion of learners, these learners would readily accept to bear part of the cost of their own education and that of their offspring.

In accordance with the nature of the structure of each of the typologies of basic education that would be offered, budgetary allocations would be different. With the help of qualified persons, budget lines can be drawn and potential contributions of each party (the state, learners, development partners [where applicable]) can be specified.

\section{Limitations of this work}

This article assumes that the livelihood-linked system of education discussed here is dynamic enough to adjust to changes in the world. While this is true to some extent, it has been shown that adjustments of these forms of education systems to changing circumstances are neither fast enough nor do they go far enough to encompass many major aspects of the rapid global changes happening around them.

Hence, the importance of buying into the periodic interventions recommended earlier on by Krätli (2001).

\section{Conclusion}

This article does not in any way suggest that the Sub-Saharan African space should be deschooled. In fact schooling should continue to be encouraged within the African environment. However, the assessment of one and a half centuries of schooling having revealed poor achievement in respect to the extent to which learning has promoted socio-economic development, this article proposes a complementary and sustainable approach to the supply of basic education and learning within Sub-Saharan Africa.

This recommendation would not be difficult to execute as all that is required is a bit of political will and strategic interventions. Examples of these kinds of initiatives having been tried on the African continent before, it will be easy to garner human, material and technological resources to assist in reviving these initiatives with the aim to implement on a larger scale.

While one is not oblivious of the fact that a few local and global interests may see their own influence and hegemony eroded through the eventual success of an initiative such as this, it must be admitted that the whole of this article stands like an advocacy to common sense and human compassion.

\section{References}

African Studies Centres. (2016). Islam in Nigeria [Internet]. 2016. Retrieved from http://www.ascleiden.nl/content/webdossiers/islam-nigeria.

Akinyemi S., Ofem, B., \& Ikuenomore S. (2012). Graduate turnout and graduate employment in Nigeria. International Journal. of Humanity and Social Sciences, 2(14), 257-265.

Babalola J. B. (2007). Reinventing Nigerian higher education for youth employment in a competitive global economy [Internet]. 2007. Retrieved from http://www.gracembipomfoundation.org2007

Balaam D. N., \& Dillman B. (2015). Introduction to international political economy. London: Routledge

Bassey G., \& Atan J. (2012). Labour market distortions and university graduate unemployment in Nigeria: Issues and remedies. Curr. Research Journal. of Econonomic Theories., 4(3), 67-76.

Berger P., \& Luckmann T. (1991). The social construction of reality. New York: Penguin Books.

Biao, I. (2015). Lifelong Learning as an Instrument for Human Capital Development in Benin. International Review of Education, 61(5), 631-653. https://doi.org/10.1007/s11159-015-9520-y

Biao I. (2013a). Adult Education: The alpha and omega of all education [Internet]. University of Botswana; 2013. Retrieved from http://www.medupe.ub.bw/articles/1659905.10092/1.PDF 
Biao, I. (1991). Towards a Political Commitment Approach to the Provision of Education for All in Nigeria. Lagos: Text and Leisure Publishers.

Biao, I. (2001). Background to the Introduction of UNICEF Non - Formal Education Curricula into Nigeria Benin City: 1994 NMEC Workshop series. Abuja: NMEC.

Biao, I. (2013b). Higher education and employment creation through community engagement within the African space $\quad$ [Internet]. $2013 . \quad$ Retrieved from http://bothouniversity.co/botho2014/buirc/downloads/BUIRC2013booklet.pdf

Blaug M. (1978). Economic theory in retrospect. London: Cambridge University Press.

Blunden A. (2012). Ontogenis, ethonogenesis, sociogenesis and phylogenesis [Internet]. Home Mira; 2012. Retrieved from http://home.mira.net/ andy/works/ontogenesis.htm

Callaway, B., \& Creevey, L. (1994). The heritage of Islam: Women, religion and politics in West Africa. Indiana: Indiana University Press.

Crowder M. (1980). The story of Nigeria. UK: Faber.

Diop, N. et al. (2004). The TOSTAN evaluation of a community based education programme in Senegal [Internet]. Retrieved from https://www.k4health.org/sites/TOSTAN-Evaluation-CommBasedSenegal.pdf

Fiske E. (2000). World Education Forum [Internet]. UNESCO. Retrieved from http://unesdoc.unesco.org/images/.pdf

Gerhart G. (1995). Review of 'The heritage of Islam: Women, religion and politics in West Africa'[Internet]. 1995 Retrieved from http://www.foreignaffairs.com

Gomez M. (1977). Non-formal education and teacher participation in the People's Republic of Benin. Commissioned case [Internet]. Study Retrieved from http://unesdoc.unesco.org/images/0002/000275/027517eb.pdf

Gordon L. (2011). Fanon and development: A philosophical look [Internet]. CODESRIA. Retrieved from http://www.codesria.org/spip.php?article1297

Hagnonnou B. (2005). Education des Adultes \& Formation des Formateurs. Cotonou: AlphaDev.

Kayaoglu N. (2012). The use of mother tongue in foreign language teaching from teachers' practice and perspective. Pamukkale Univers. Journ. of Educ., 32(II), 25-35.

Keita L. (2011). Philosophy and African development: Theory and practice [Internet]. CODESRIA; 2011. Retrieved from http://www.codesria.org/spip.php?article1297

Kioko A. (2015). Why schools should teach young learners in home language [Internet]. Retrieved from https://www.britishcouncil.org/voices-magazine/why-schools-should-teach-young-learners-home-language

Ki-Zerbo J. (1991). Histoire générale de l'Afrique. Tome IV: L'Afrique du XIIe au XVIe siècle. Paris: UNESCO.

Kraätli S. (2001). Education provision to nomadic pastoralists: A literature review [Internet]. Retrieved from http://www.eldis.org/fulltext/saverio.pdf

Lawrence B. A. (2017). The meals that change children's lives [Internet]. 2017. Retrieved from https://insight.wfp.org/more-than-just-a-meal-918159b1a90d

Malthus, T., \& Ricardo, D. (1817). Wealth and poverty [Internet]. Study More; 1817. Retrieved from http://studymore.org.uk/she7.htm

Nsamenang B. (2006). Human ontogenesis: An indigenous African view on development and intelligence. Intern. Journal of Psych., 41(4), 293-297. https://doi.org/10.1080/00207590544000077

OECD. (2015). Education at a glance [Internet]. OECD. Retrieved from http://www.oecd.org/edu/education-at-a-glance-19991487.htm

Ojokheta, K. (2007). Paulo Freire's literacy teaching methodology: Application and implications of the methodology in basic literacy classes in Ibadan-Oyo State-Nigeria. DVV, 69, 111-120

Sagepub. (2017). The concept of culture [Internet]. 2017. Retrieved from https://us.sagepub.com/sites/default/files/upm-binaries/48150_ch_1.pdf

Teferra D. (2015). Charting African higher education-Perspectives at a glance. Intern. Journal of Africa Higher 
Educ., 1(1), 9-21.

Tilak J. (2009). Financing higher education in Africa [Internet]. Grace Mbipom Foundation. Retrieved from http://www.gracembipomfoundation.org2007

Torres, RM. (2003). Lifelong learning in the south: Critical issues and opportunities of adult education. Stockholm: SIDA.

Turner, R. (2008). Neo-liberal ideology: History, concepts and policies. Edinburgh: Edinburgh University Press.

Umejesi IO. (1992). The spread of Islam in Nigeria. Orita, 24(2), 85-96.

UNESCO. (1990). World Conference on EFA, Jomtien [Internet]. UNESCO. Retrieved from http://www.unesco.org/new/en/education/themes/leading-the-international-agenda/education-for-all/the-efa-mo vement/jomtien-1990/

UNESCO. (2007). Operational definition of basic education: Thematic framework. Paris: UNESCO.

UNICEF. (2008). Child friendly schools [Internet]. 2008. Retrieved from https://www.unicef.org/cfs/

UNICEF. (2008). Monitoring learning achievement in Nigeria's adult education centers. Abuja: UNICEF.

UNICEF. (2016). Education: secondary net attendance rate [Internet]. UNICEF. Retrieved from http://unicef.globaldatebases/

United Nations. (2015). The millennium development goals report 2015. New York: UN.

World Bank. (2015). Tertiary education-Higher education [Internet]. 2015. Retrieved from $\mathrm{http}: / /$ web.worldbank.org/EXTEDUCATION/0contentMDK:2282386,00.html 